\title{
Elephant Poaching and Vegetation Changes in Uganda
}

\author{
John Hatton, Clare Hobsley and Nick Smart
}

In the 1970s, under Idi Amin's rule, poaching decimated mammal populations in Uganda and, as a result of the drop in browsing and grazing pressure, uniform scrub and woodland are replacing the species-rich grasslands.

The greatest slaughter of Uganda's animals occurred in the 1978 Tanzanian war of liberation, when soldiers loyal to Amin used the national parks as escape routes from the advancing Tanzanian troops. These remnants of Amin's army used their sophisticated weaponry with devastating effect, causing declines in the number of elephant Loxodonta africana, white rhino Ceratotherium simum cottoni, black rhino Diceros bicornis, topi Damaliscus lunatus jimela, Jackson's hartebeest Alcelaphus buselaphus jacksoni, Uganda kob Kobus kob thomasi and defassa waterbuck $K$. defassa. ${ }^{4}$

As the numbers of grazing and browsing animals decreased, a marked vegetation change occurred with the result that scrub, especially Acacia sieberiana, now covers large areas. Recognizing that this situation, where a major mammal species, the elephant, has been reduced from overpopulation to almost no population in a very short period of time, is probably unique, a United Nations report in 1981 recommended that it be investigated. ${ }^{6}$ In the same year Uganda's relative stability enabled us to survey the vegetation in the Chobe sector of Kabalega Falls National Park.

In 1967, vegetation plots had been set up ${ }^{5}$ to investigate the effects of burning and the exclusion of large herbivores on the vegetation, in response to a plea by Buechner and Dawkins, who were concerned about the conversion of woodland and forest to uniform grassland due to the large numbers of elephant then present. Exclusion plots surrounded by elephant-proof ditches were laid out in two vegetation types: one in grassland (savanna with scattered Acacia sieberiana trees) and one in woodland (dominated by Combretum binderianum and Terminalia glaucescens).

We monitored these plots in November 1981 and found dramatic changes; what was once grassland now consisted of a dense stand of Acacia, some up to $16 \mathrm{~m}$ high. The canopy was almost complete and the understorey dominated by two prolifically spreading herbaceous species, A calypha bipartita and Achyranthes aspera. Thus, after only 14 years exclusion of herbivores, the botanical composition of the grassland had changed completely; all the important grasses had been lost including Sporobolus pyramidalis, Hyparrhenia filipendula, $H$. rufa and Setaria spp. It is evident that when grazing and browsing pressure is removed from the grassland ecosystem a relatively species-poor habitat replaces the grasses that are important for grazing animals.

Even more interesting were the changes in the 1967 control plots. These had been grazed and browsed over the intervening years, but dense Acacia scrub, with trees up to $3 \mathrm{~m}$ tall, was invading the grazed areas in both grassland and woodland, apparently a direct response to the recent decline in herbivores, especially elephants. In 1980 Eltringham and Malpas estimated that the elephant population in Kabalega Falls National Park had dropped from 14,000 in 1973 to 1500 , a reduction of 90 per cent. ${ }^{2}$ If the Acacia scrub is allowed to establish to the extent found in the plots with no grazing and browsing, it could have important repercussions on the speciesrichness of the grasslands. 
What is happening in Uganda contrasts directly with the situation in Zimbabwe where elephant numbers have increased after ten years of civil war and in some parks now exceed the carrying capacity. ${ }^{3}$ Forest has been destroyed and replaced by open grassland. Maintaining an optimal relationship between large herbivores and their environment is one of the major conservation problems in Africa. The present situation in Uganda poses problems for wildlife management; not only is the ecological balance of the national parks being altered, but the regeneration of scrub will affect tourist 'game viewing', which the authorities hope to encourage. Burning to control Acacia regeneration is being considered.

Another solution may lie in the natural cycle of change which will occur with the expected increase in herbivore populations. The signs of this happening are hopeful, at least in the Rwenzori and Kabalega Falls National Parks, in view of the successful antipoaching operations conducted by Dr Iain Douglas-Hamilton. But in Kidepo Valley National Park in the north the situation was still unstable at the time of our visit; Sudanese soldiers, poaching for food and ivory, frequently cross the park's common border with Sudan, and so the main thrust of the anti-poaching operations is presently concentrated here.

During our visit the situation in the national parks appeared to be stabilizing, and we were able to carry out our research without problems or concern for our safety. If the whole of Uganda becomes stable, the national parks might once again become a major tourist attraction, providing a boost for the economy.

\section{Acknowledgments}

We would like to thank the Board of Trustees for Uganda National Parks for permission to carry out this research and the Uganda Institute of Ecology for valuable assistance. The vegetation survey was sponsored by the Royal Society, the Linnean Society, the Royal Geographical Society, University
Exclosure plot, ungrazed since 1967 , surrounded by grassland which has been invaded by Acacia scrub since the recent decline in elephant numbers.

College Expedition Fund and the University of London (Central Research Fund). Dr Iain Douglas-Hamjlton offered much practical assistance, enabling us to obtain aerial photographs of the vegetation plots. Professor Spence has also given considerable encouragement and made data available from previous surveys.

\section{References}

1. BUECHNER, H.K. and H.C. DAWKINS. 1961. Vegetation change induced by elephants and fire in Murchison Falls National Park, Uganda. Ecology 42: 752-66.

2. ELTRINGHAM, S.K. and R.C. MALPAS. 1980. The decline in elephant numbers in Rwenzori and Kabalega Falls National Parks, Uganda. Afr. J. Ecol. 18:73-6.

3. HALLAGAN, J. B. 1981. Elephants and war in Zimbabwe. Oryx 16, 2: 161-4.

4. MALPAS, R.C. 1981. Elephant losses in Uganda - and some gains. Oryx 16, 1: 41-4.

5. SPENCE, D.H.N. and ANGUS, A. 1971. African grassland management - burning and grazing in Murchison Falls National Park, Uganda. In: The Scientific Management of Animal and Plant Communities for Conservation. Eds. E. Duffey and A. S. Watt, Blackwell, Oxford.

6. United Nations Development Programme, World Tourism Organization Report, Uganda (UGA/80/ 008). Wildlife in Uganda, Annex I. Madrid 1981.

John Hatton, Clare Hobsley and Nick Smart, Ecology and Conservation Unit, Dept of Botany and Microbiology, University College London, Gower Street, London WC1E 6BT, UK. 